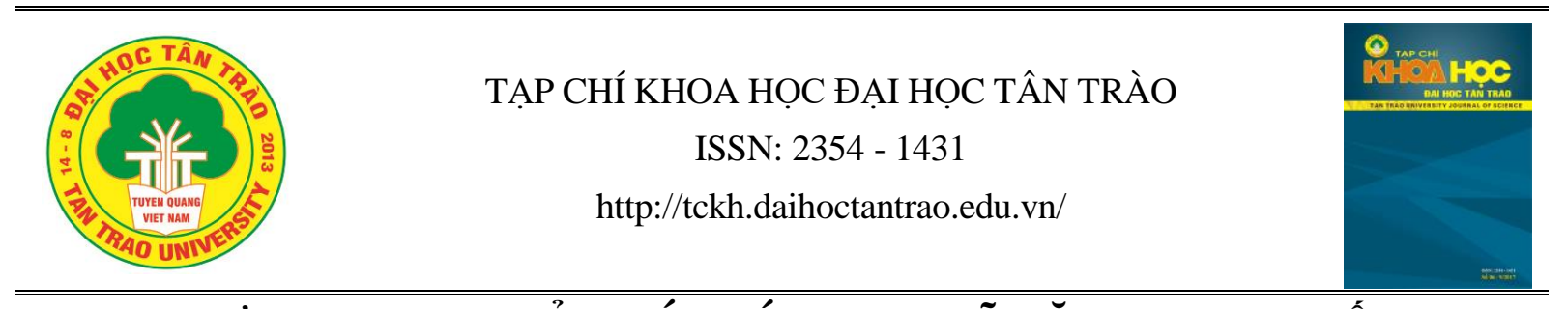

\title{
THỤC TRẠNG QUẢN LÝ GIÁO DỤC KĨ NĂNG GIAO TIẾP CHO HỌC SINH TIỂU HỌC THÀNH PHỐ TUYÊN QUANG THEO ĐỊNH HƯỚNG CHƯƠNG TRİNH GIÁO DỤC PHỔ THÔNG 2018
}

Hoàng Trà $M y^{a, *}$

${ }^{a}$ Truờng Tiểu hoc Ỷ La

*Email: mythuatmy@gmail.com

\section{Thông tin bài viết}

Ngày nhận bài:2/5/2020

Ngày duyệt đăng:10/6/2020

Tù khóa:

Khảo sát, đánh giá, quản lý kỹ năng giao tiếp, hoc sinh tiểu học

\section{Tóm tắt}

Để đánh giá đúng thực trạng quản lý giáo dục kỹ năng giao tiếp cho học sinh Tiểu học thành phố Tuyên Quang theo định hướng chương trình giáo dục phổ thông 2018 tác giả đã khảo sát thực trạng công tác quản lý một cách khách quan trên các đối tượng: cán bộ quản lý, giáo viên, tổng phụ trách Đội, phụ huynh học sinh, nhằm đánh giá đúng thực trạng quản lý GDKNGT và đưa ra các giải pháp QLGDKNGT phù hợp để nâng cao chất lượng giáo dục KNGT tại các trường Tiểu học trên địa bàn thành phố Tuyên Quang theo định hướng chương trình giáo dục phổ thông 2018.

\section{1. Đặt vấn đề}

Quản lý giáo dục kỹ năng giao tiếp (GDKNGT) cho học sinh Tiểu học là vấn đề được quan tâm và nghiên cứu trong thời gian gần đây không chỉ ở Việt Nam mà còn được nghiên cứu ở rất nhiều nước trên thế giới. Để làm tốt công tác quản lý GDKNGT trong bối cảnh hiện nay đòi hỏi nhiều yếu tố trong đó vai trò của nhà trường là vô cùng quan trọng, tiên phong trong quá trình giáo dục các kỹ năng giao tiếp (KNGT) cho học sinh (HS) Tiểu học. Lực lượng trực tiếp làm công tác quản lý, giảng dạy là lực lượng nòng cốt hiểu rõ những đặc điểm, tình hình, mức độ nhận thức của từng đối tượng $\mathrm{HS}$ trong nhà trường qua các quá trình học tập và rèn luyện để từ đó đưa ra các giải pháp thích hợp nhằm nâng cao chất lượng GDKNGT cho HS. Nghiên cứu này tìm hiểu thực trạng quản lý GDKNGT cho HS Tiểu học tại thành phố Tuyên Quang. Kết quả nghiên cứu sẽ là cơ sở thực tiễn để đề xuất các biện pháp nâng cao chất lượng quản lý GDKNGT cho HS Tiểu học tại thành phố Tuyên Quang theo định hướng chương trình giáo dục phổ thông 2018.

\section{2. Đối tượng và phương pháp nghiên cứu}

\section{1. Đối tự̛ng nghiên cứu}

Tác giả khảo sát trên 232 đối tượng: cán bộ quản lý giáo dục: 11 người, GV Tiểu học: 120 người, tổng phụ trách Đội: 6 người, phụ huynh HS: 95 người từ các trường Tiểu học trên địa bàn thành phố Tuyên Quang.

\subsection{Phương pháp nghiên cúu}

- Phương pháp quan sát, phương pháp phỏng vấn: Phương pháp này được sử dụng để có những thông tin ban đầu về thực trạng quản lý GDKNGT cho HS Tiểu học thành phố Tuyên Quang theo định hướng chương trình giáo dục phổ thông 2018.

- Phương pháp điều tra bằng phiếu hỏi: Thiết kế bảng hỏi, khảo sát trên các đối tượng nghiên cứu nhằm tìm hiểu thực trạng quản lý GDKNGT cho HS Tiểu học thành phố Tuyên Quang theo định hướng chương trình giáo dục phổ thông 2018.

- Phương pháp sử dụng toán thống kê: Để xử lý các số liệu thu được.

\section{Nội dung nghiên cứu và bàn luận}


KNGT thể hiện trong quá trình tiếp xúc của HS với các thành viên trong gia đình, nhà trường và các mối quan hệ xã hội, KNGT được hình thành dựa trên những điều kiện tâm sinh lý lứa tuổi của $\mathrm{HS}$, phụ thuộc vào môi trường xã hội, thể hiện tính kĩ thuật qua cách sử dụng các thao tác, hành vi, ngôn ngữ, điệu bộ một cách hợp lí nhằm đạt mục đích giao tiếp của các chủ thể giao tiếp. KNGT của HS Tiểu học bao gồm các kỹ năng: chào hỏi, lắng nghe, xử lý các tình huống trong giao tiếp, biết nói lời cảm ơn, lời xin lỗi và biết cách từ chối yêu cầu, đề nghị, phán đoán, xử lý thông tin [1][5].

Quản lý GDKNGT được thể hiện nhất quán trong các khâu: xây dựng kế hoạch, xác định nhiệm vụ, nội dung, hình thức tổ chức và kiểm tra, đánh giá kết quả GDKNGT [3]. Quá trình GDKNGT cho HS Tiểu học theo định hướng chương trình phổ thông 2018 phụ thuộc vào mục tiêu, phương pháp giáo dục, năng lực của đội ngũ GV, lực lượng giáo dục trong và ngoài nhà trường, tính tích cực chủ động tham gia học hỏi của HS [2]. Quản lý GDKNGT có một vai trò quan trọng giúp cho HS Tiểu học có được môi trường rèn luyện KNGT tốt, từ đó tổ chức tốt các mối quan hệ giao tiếp trong học tập và trong cuộc sống, phát triển nhân cách toàn diện, từ đó các em sẽ có nền móng vững chắc để trở thành những công dân mẫu mực, tự tin đương đầu với những thách thức trong quá trình hội nhập quốc tế [4][5]. Các nội dung và kết quả khảo sát được trình bày và phân tích dưới đây.

\subsection{Thực trạng nhận thức của cán bộ quản lý, giáo viên} và phụ huynh học sinh về GDKNGT cho HS ở các trường Tiểu học tại thành phố Tuyên Quang

3.1.1. Nhận thức của cán bộ quản lý, giáo viên, phu huynh học sinh về tầm quan trọng của giao tiếp trong sư hìn thành và phát triển nhân cách con nguoòi

Sau khi tổng hợp 232 phiếu hỏi của cán bộ quản lý $(\mathrm{CBQL}), \mathrm{GV}$ và phụ huynh $\mathrm{HS}$ về nội dung đánh giá nhận thức về vai trò của giao tiếp trong cuộc sống con người, khái niệm giao tiếp, tầm quan trọng của GDKNGT cho HS, chúng tôi thu được kết quả thể hiện số liệu tại bảng 1 như sau:

Bảng 1. Nhận thức của CBQL, GV, phụ huynh HS về vai trò của giao tiếp trong cuộc sống

\begin{tabular}{|c|l|c|c|}
\hline TT & \multicolumn{1}{|c|}{ Nội dung } & Số lượng & Tỷ lệ \\
\hline 1 & $\begin{array}{l}\text { Giao tiếp có vai trò quan trọng trong việc hình thành và phát triển nhân } \\
\text { cách của con người }\end{array}$ & 23 & $9,91 \%$ \\
\hline 2 & $\begin{array}{l}\text { Giao tiếp có vai trò quyết định giúp con người truyền đạt những kinh } \\
\text { nghiệm, giải quyết các vấn đề của cuộc sống đem lại sự thành công }\end{array}$ & 43 & $18,53 \%$ \\
\hline 3 & \begin{tabular}{l} 
Tất cả các nội dung trên \\
\hline
\end{tabular}
\end{tabular}

Có 71,56\% CBQL,GV, phụ huynh HS nhận thức đầy đủ về vai trò của giao tiếp trong cuộc sống con người, điều đó khẳng định sự quan tâm tới vấn đề giao tiếp của trẻ từ phía thầy cô giáo và cha mẹ HS. Từ khi sinh ra con người đều có nhu cầu về giao tiếp, để tham gia vào các mối quan hệ trong xã hội và để giải quyết những vấn đề của cá nhân. Mỗi con người thông qua giao tiếp để điều chỉnh hành vi của bản thân cho phù hợp với chuẩn mực xã hội với các quan hệ xã hội, thông qua giao tiếp con người hình thành nên các năng lực tự ý thức, giáo dục bản thân và dần dần hoàn thiện bản thân. Để xác định đúng và đầy đủ vài trò của giao tiếp trong cuộc sống con người để tìm hiểu sâu hơn nữa về khái niệm của giao tiếp, chúng tôi tiến hành khảo sát về khái niệm KNGT với CBQL, GV, phụ huynh HS. Kết quả khảo sát như sau:

Bảng 2. Nhận thức của CBQL, GV, phụ huynh HS về khái niệm KNGT

\begin{tabular}{|c|c|c|c|}
\hline TT & \multicolumn{1}{|c|}{ Nội dung } & Số lượng & Tỷ lệ \\
\hline 1 & Kỹ năng giao tiếp là nói một điều gì đó với ai đó & 6 & $2,6 \%$ \\
\hline
\end{tabular}




\begin{tabular}{|c|l|c|c|}
\hline 2 & Kỹ năng giao tiếp là thể hiện sự truyền tải trao đổi thông tin & 8 & $3,4 \%$ \\
\hline 3 & $\begin{array}{l}\text { Kỹ năng giao tiếp là khả năng tự tin, bộc lộ bản thân chia sẻ và trao đồi } \\
\text { thông tin, xử lý thông tin với người khác bằng hình thức phi ngôn ngữ và } \\
\text { ngôn ngữ phù hợp với chuẩn mực và hoàn cảnh xã hội }\end{array}$ & 218 & $94 \%$ \\
\hline
\end{tabular}

Từ kết quả khảo sát nêu ở bảng 2 cho thấy: Có $94 \%$ CBQL, GV, phụ huynh HS nhận thức đúng và đầy đủ về khái niệm KNGT cho HS, tỷ lệ này chiếm ưu thế cao, còn hai tỷ lệ nhỏ là $2,6 \%$ và $3,4 \%$ là tỷ lệ chưa nhận thức đầy đủ về khái niệm KNGT. So sánh số liệu thống kê ở bảng 1 và bảng 2 kết hợp với đọc các báo cáo của các nhà trường tham gia khảo sát cho thấy có sự thống nhất với nhau, điều đó khẳng định các nhà trường đã làm tốt công tác tập huấn, tuyên truyền về nhận thức đến cán bộ, GV và phụ huynh HS để họ hiểu được vai trò của giao tiếp trong đời sống con người, trong sự phát triển nhân cách của con người và khái niệm về KNGT. Các thầy cô giáo và cha mẹ HS còn khẳng định mức độ cần thiết để GDKNGT cho HS Tiểu học qua số liệu ở bảng 3 khi tỷ lệ khảo sát thu về đạt được là $100 \% \mathrm{CBQL}, \mathrm{GV}$, phụ huynh HS đều đánh giá chọn mức độ quan trọng và rất quan trọng trong việc GDKNGT cho trẻ.

Bảng 3. Nhận thức của $\mathrm{CBQL}, \mathrm{GV}$, phụ huynh HS về mức độ cần thiết để GDKNGT cho HS tiểu học

\begin{tabular}{|c|l|c|c|}
\hline TT & \multicolumn{1}{|c|}{ Nội dung đánh giá mức độ } & Số lượng & Tỷ lệ \% \\
\hline 1 & $\begin{array}{l}\text { Rất quan trọng cần GDKNGT cho học sinh } \\
\text { càng sớm càng tốt }\end{array}$ & 198 & $85,34 \%$ \\
\hline 2 & $\begin{array}{l}\text { Quan trọng nên GDKNGT cho học sinh từ bậc } \\
\text { học Mầm non }\end{array}$ & 34 & $14,66 \%$ \\
\hline 3 & $\begin{array}{l}\text { Không quan trọng dần dần trẻ khác tự có các } \\
\text { KNGT }\end{array}$ & 0 & 0 \\
\hline
\end{tabular}

Qua kết quả khảo sát của Bảng 1 và Bảng 2 , Bảng 3 cho thấy phần lớn $\mathrm{GV}, \mathrm{CBQL}$ và phụ huynh $\mathrm{HS}$ đã có nhận thức tốt về vai trò, khái niệm KNGT, tầm quan trọng của GDKNGT cho trẻ, tuy nhiên từ nhận thức đến việc làm là một khoảng cách khá xa đòi hỏi người làm công tác GDKNGT cho HS Tiểu học phải có điều kiện, có nền tảng kiến thức và có sự chỉ đạo dẫn dắt khoa học phù hợp của các nhà quản lý giáo dục nhằm giúp đỡ cán bộ $\mathrm{GV}$, phụ huynh HS vượt qua được các rào cản đó. Chính vì lý do này, chúng tôi tiến hành tiếp nội dung khảo sát tìm hiểu về tầm quan trọng của việc quản lý GDKNGT cho HS Tiểu học và kết quả thu được như sau:

Bảng 4. Nhận thức về mức độ cần thiết của quản lý GDKNGT cho HS Tiểu học

\begin{tabular}{|c|l|c|c|}
\hline Nội dung & \multicolumn{1}{|c|}{ Mức độ } & Số lượng & Tỷ lệ \% \\
\hline \multirow{3}{*}{ Tầm quan trọng } & Rất quan trọng & 168 & 72,4 \\
\cline { 2 - 4 } & Quan trọng & 61 & 26,3 \\
\cline { 2 - 4 } & Không quan trọng & 3 & 1,3 \\
\hline
\end{tabular}

Kết quả ở Bảng 4 cho thấy, chỉ có $1,3 \%$ cho rằng mức độ không quan trọng của quản lý GDKNGT, còn lại tỷ lệ cao cho đánh giá mức độ quan trọng và rất quan trọng là $26,3 \%$ và $72,4 \%$, điều này khẳng định $\mathrm{GV}, \mathrm{CBQL}$ và phụ huynh HS thành phố Tuyên Quang đã có những nhận thức đúng đắn về khái niệm giao tiếp, vai trò, và mức độ cần thiết của hoạt động quản lý GDKNGT trong các trường Tiểu học

\subsection{Thực trạng lập kế hoạch GDKNGT cho HSở các trường Tiểu học thành phố Tuyên Quang theo}


định hướng chương trình giáo dục phổ thông 2018

Kết quả khảo sát thực trạng lập kế hoạch GDKNGT cho HS ở các trường Tiểu học thành phố Tuyên Quang theo định hướng chương trình giáo dục phổ thông 2018 thu được thể hiện ở bảng 5 dưới đây.

Bảng 5. Tổng hợp kết quả đánh giá của GV về chất lượng kế hoạch GDKNGT của CBQL tại các trường tiểu học tại thành phố Tuyên Quang

\begin{tabular}{|c|c|c|c|c|c|c|c|}
\hline \multirow{3}{*}{$\mathbf{T t}$} & \multirow{3}{*}{ Nội dung kế hoạch GDKNGT } & \multicolumn{6}{|c|}{ Mức độ } \\
\hline & & \multicolumn{2}{|c|}{ Tốt } & \multicolumn{2}{|c|}{ Bình thường } & \multicolumn{2}{|c|}{ Chưa tốt } \\
\hline & & SL & $\%$ & SL & $\%$ & SL & $\%$ \\
\hline 1 & Khảo sát thực trạng trước khi lập kế hoạch & 19 & 13,87 & 46 & 33,58 & 72 & 52,55 \\
\hline 2 & Xác định mục tiêu GDKNGT & 21 & 15,33 & 42 & 30,66 & 74 & 54,01 \\
\hline 3 & $\begin{array}{l}\text { Dự kiến nhân lực thực hiện kế hoạch dự kiến } \\
\text { kinh phí và các điều kiện cơ sở vật chất }\end{array}$ & 35 & 25,55 & 65 & 47,44 & 37 & 27 \\
\hline 4 & $\begin{array}{l}\text { Lên kế hoạch thực hiện công việc nội dung } \\
\text { các mốc thời gian, hình thức tổ chức, biện } \\
\text { pháp thực hiện để hoàn thành từng nội dung } \\
\text { KHGDKNGT }\end{array}$ & 22 & 16,06 & 63 & 45,98 & 52 & 37,96 \\
\hline 5 & $\begin{array}{l}\text { Phân công công việc phù hợp, cụ thể cho lực } \\
\text { lượng GDKNGT }\end{array}$ & 20 & 14,60 & 51 & 37,23 & 66 & 48,17 \\
\hline 6 & $\begin{array}{l}\text { Kiểm tra thực hiện nội dung kế hoạch } \\
\text { GDKNGT theo tuần, tháng, kỳ, đột xuất }\end{array}$ & 26 & 18,98 & 53 & 38,69 & 58 & 42,35 \\
\hline 7 & $\begin{array}{l}\text { Đánh giá, rút kinh nghiệm và điều chỉnh khi } \\
\text { cần thiết }\end{array}$ & 32 & 23,36 & 51 & 37,23 & 54 & 39,41 \\
\hline & Trung bình cộng & 25 & 18,25 & 53 & 38,69 & 59 & 43.06 \\
\hline
\end{tabular}

Qua kết quả khảo sát ở Bảng 5 cho thấy, chất lượng lập kế hoạch GDKNGT cho HS Tiểu học tại thành phố Tuyên Quang chưa được các nhà trường đặc biệt quan tâm chú trọng, KNGT chưa trở thành một môn học mà nội dung chỉ được lồng ghép trong các hoạt động giáo dục tại nhà trường, ở một số trường GDKNGT là một phần nhỏ trong nội dung giáo dục kỹ năng sống cho nên việc khảo sát thực trạng trước khi lập kế hoạch còn chưa được coi trọng (52,55\% tỷ lệ đánh giá mức độ chưa tốt) vì vậy, việc xác định mục tiêu còn chung chung (tỷ lệ đánh giá chưa tốt chiếm 54,01\%), phân công công việc cho lực lượng GDKNGT chưa phù hợp dẫn đến chất lượng kế hoạch thực hiện GDKNGT còn chưa được chất lượng và hiệu quả cao, có 43,06\% chất lượng chưa tốt trong đó chất lượng tốt của các tiêu chí trong kế hoạch của hiệu trưởng chiếm 18,25\%.

\subsection{Thực trạng chỉ đạo hoạt động GDKNGT cho HS} ở các trường Tiểu học thành phố Tuyên Quang theo định hướng chương trình giáo dục phổ thông 2018

Thực trạng chỉ đạo GDKNGT căn cứ vào rất nhiều các nội dung để đánh giá tuy nhiên tác giả đã chọn lựa 5 nội dung cơ bản nhất để tiến hành khảo sát với ba đối tượng CBQL, $\mathrm{GV}$, tổng phụ trách Đội và thu được kết quả thể hiện ở Bảng 6 và Biểu đồ 1 dưới đây:

Dựa vào số liệu bảng 6 , chúng tôi vẽ biểu đồ để thể hiện mối tương quan giữa các nội dung đánh giá thực trạng chất lượng công tác quản lý GDKNGT như sau 
Bảng 6. Đánh giá thực trạng chất lượng công tác quản lý GDKNGT

\begin{tabular}{|c|l|c|c|c|c|c|c|}
\hline \multirow{2}{*}{ STT } & \multicolumn{2}{|c|}{ Nội dung đánh giá } & \multicolumn{5}{|c|}{ Mức độ đánh giá } \\
\cline { 3 - 8 } & & \multicolumn{2}{|c|}{ Rất tốt } & \multicolumn{2}{|c|}{ Tốt } & \multicolumn{2}{c|}{ Chưa tốt } \\
\cline { 3 - 9 } & SL & $\%$ & SL & $\%$ & SL & $\%$ \\
\hline 1 & $\begin{array}{l}\text { Tổ chức tập huấn nâng cao nhận thức } \\
\text { cho cán bộ, GV về GDKNGT }\end{array}$ & 12 & 8,76 & 74 & 54,01 & 51 & 37,23 \\
\hline 2 & $\begin{array}{l}\text { Chỉ đạo hình thức GDKNGT cho HS } \\
\text { qua các môn học }\end{array}$ & 5 & 3,65 & 45 & 32,85 & 87 & 63,5 \\
\hline 3 & $\begin{array}{l}\text { Xây dựng thực hiện nội dung hoạt } \\
\text { động GDKNGT cho HS lồng ghép } \\
\text { với công tác sinh hoạt chủ nhiệm lớp }\end{array}$ & 8 & 5,84 & 41 & 29,93 & 88 & 64,23 \\
\hline 4 & $\begin{array}{l}\text { Chỉ đạo tích hợp nội dung hoạt động } \\
\text { GDKNGT với hoạt động GDNGLL }\end{array}$ & 3 & 2,19 & 35 & 25,55 & 99 & 72,26 \\
\hline 5 & $\begin{array}{l}\text { Phối hợp các lực lượng giáo dục } \\
\text { hoạt động GDKNGT của đơn vị }\end{array}$ & 11 & 8,03 & 55 & 40,15 & 71 & 51,82 \\
\hline & Trung bình cộng & 7,8 & 5,69 & 50 & 36,50 & 79,2 & 57,81 \\
\hline
\end{tabular}

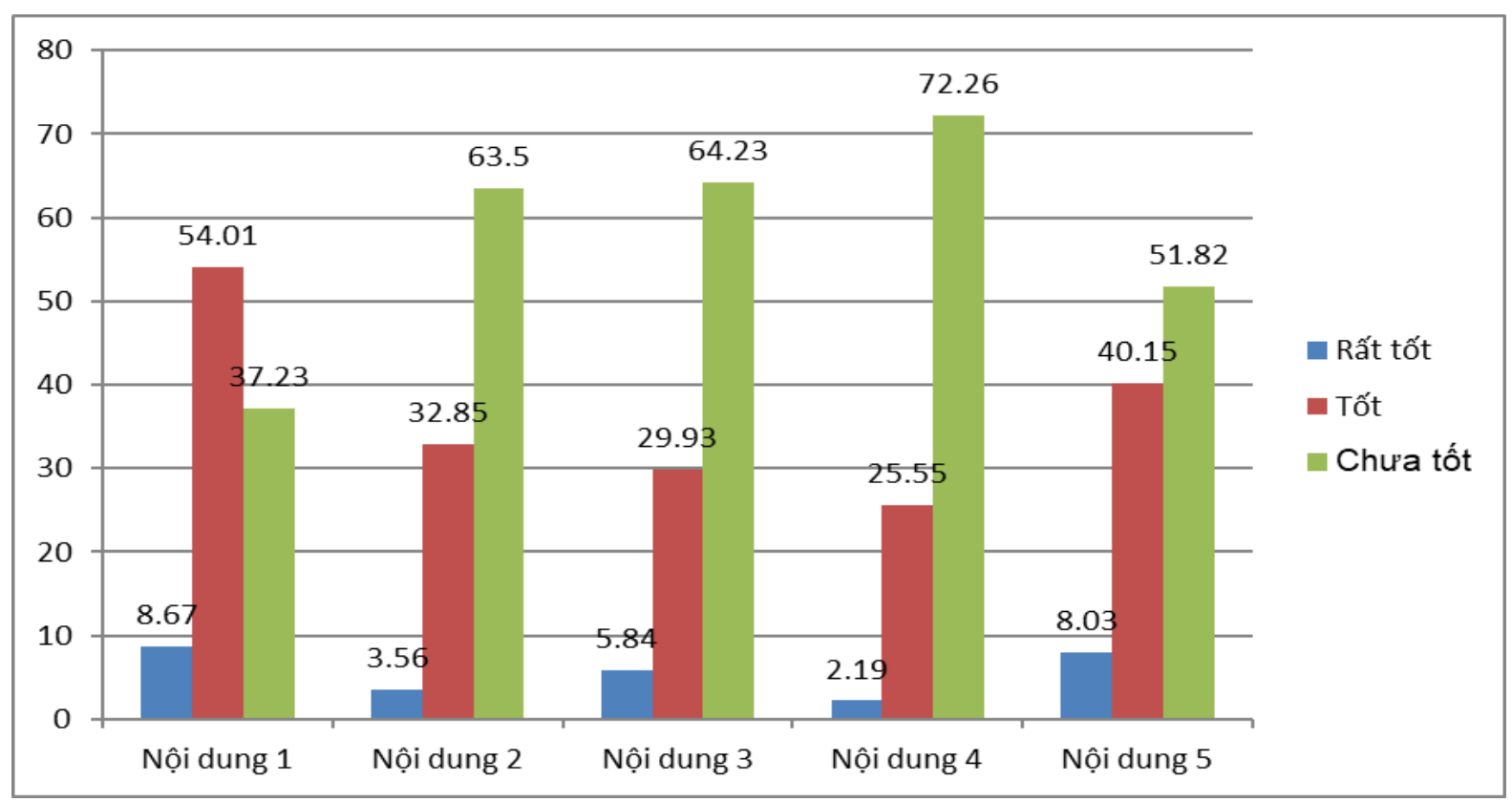

Biểu đồ 1. Đánh giá thực trạng công tác quản lý GDKNGT

Qua kết quả khảo sát thu được thể hiện ở bảng 6 và biểu đồ 1 chúng tôi có nhận xét như sau: Về công tác tổ chức tập huấn nâng cao nhận thức cho cán bộ $\mathrm{GV}$ về GDKNGT hầu hết các trường đã tổ chức tốt công tác tuyên truyền nhận thức về GDKNGT và tập huấn nâng cao nhận thức tới toàn thể $\mathrm{CBGV}$ trong nhà trường biểu hiện ở kết quả đánh giá $(54,01 \%)$ thực hiện tốt. Tuy nhiên, dựa vào kết quả của 4 tiêu chí còn lại thì cho thấy còn nhiều hạn chế về công tác chỉ đạo, hình thức
GDKNGT cho HS qua các môn học thực hiện chưa tốt (63,5\%); Xây dựng thực hiện nội dung hoạt động GDKNGT cho HS lồng ghép với công tác sinh hoạt chủ nhiệm lớp $(64,23 \%)$ thực hiện chưa tốt; Chỉ đạo tích hợp nội dung hoạt động GDKNGT với hoạt động GDNGLL (72,26\%); Phối hợp các lực lượng giáo dục hoạt động GDKNGT của đơn vị (51,82\%). Tổng hợp trung bình thực hiện chưa tốt của các tiêu chí là ( 57,81\%) xếp ở mức độ trung bình. 
3.4. Thực trạng kiểm tra, đánh giá kết quả thực hiện GDKNGT cho HS ở các trường Tiểu học thành phố Tuyên Quang theo định hướng chương trình giáo dục phổ thông 2018

Bảng 7. Thực trạng công tác kiểm tra, đánh giá kết quả GDKNGT cho HS

\begin{tabular}{|c|c|c|c|c|c|c|c|}
\hline \multirow{3}{*}{ TT } & \multirow{3}{*}{ Nội dung thực hiện } & \multicolumn{6}{|c|}{ Mức độ thực hiện } \\
\hline & & \multicolumn{2}{|c|}{ Thường xuyên } & \multicolumn{2}{|c|}{ Đôi khi } & \multicolumn{2}{|c|}{ Không thụ̣c hiện } \\
\hline & & SL & $\%$ & SL & $\%$ & SL & $\%$ \\
\hline 1 & Kiểm tra hằng tháng & 10 & 7,3 & 74 & 54,01 & 53 & 38,69 \\
\hline 2 & Kiểm tra theo học kỳ & 32 & 23,36 & 105 & 76,64 & 0 & 0 \\
\hline 3 & $\begin{array}{l}\text { Kiểm tra đột xuất thực } \\
\text { hiện các nội dung } \\
\text { GDKNGT }\end{array}$ & 8 & 5,84 & 32 & 23,36 & 97 & 70,8 \\
\hline 4 & Kiểm tra cuối năm học & 137 & 100 & 0 & 0 & 0 & 0 \\
\hline 5 & $\begin{array}{l}\text { Đánh giá, rút kinh nghiệm, } \\
\text { khen thưởng }\end{array}$ & 11 & 8,3 & 57 & 41,61 & 69 & 50,36 \\
\hline 6 & $\begin{array}{l}\text { Thực hiện các điều chỉnh } \\
\text { khi cần thiết }\end{array}$ & 7 & 5,11 & 49 & 35,77 & 81 & 59,12 \\
\hline
\end{tabular}

Kết quả khảo sát tại bảng 7 cho thấy tỷ lệ \% việc kiểm tra của nhà trường thể hiện qua sự đánh giá của $\mathrm{CBQL}$ và GV kiểm tra hằng tháng không thực hiện là 38,69\%, kiểm tra đột xuất không thực hiện 70,8\%. Các nhà trường có thực hiện công tác kiểm tra nhưng chủ yếu vào cuối kỳ và cuối năm học. Trao đổi với $\mathrm{CBQL}$ và $\mathrm{GV}$ chúng tôi thấy việc kiểm tra, đánh giá kết quả GDKNGT của các nhà trường chủ yếu là kiểm tra nội dung giáo án của GV, lấy kết quả HS cuối kỳ và cuối năm để làm cơ sở đánh giá việc GDKNGT của GV đối với HS, chưa quan tâm tới kết quả của các hoạt động tập thể và hoạt động của Liên Đội. Các tiêu chí đánh giá xây dựng chưa cụ thể, cho nên việc đánh giá và khen thưởng còn chưa chính xác, công tác điều chỉnh chưa phù hợp và kịp thời. Các nội dung trên khẳng định công tác kiểm tra GDKNGT của các nhà trường chưa có kế hoạch cụ thể, chưa được quan tâm xây dựng như một mục riêng mà còn lồng ghép vào các nội dung kiểm tra khác của nhà trường, từ đó cho thấy: Hiệu trưởng các trường Tiểu học tại thành phố Tuyên Quang vẫn còn chưa chú trọng tới công tác kiểm tra, đánh giá hoạt động GDKNGT cho HS, cho nên nội dung kiểm tra chưa rõ ràng, cụ thể. Từ thực tế đó đặt ra yêu cầu cần có các giải pháp tăng cường chức năng kiểm tra, đánh giá việc thực hiện GDKNGT cho HS Tiểu học.

\section{Kết luận}

Qua nghiên cứu thực trạng quản lý GDKNGT của các trường Tiểu học tại thành phố Tuyên Quang cho thấy, vấn đề quản lý hoạt động GDKNGT cho HS Tiểu học thành phố Tuyên Quang đã được Hiệu trưởng các trường Tiểu học chỉ đạo thực hiện và đã đạt được những thành tựu nhất định. Tuy nhiên, do nhiều nguyên nhân chủ quan và khách quan, việc quản lý hoạt động GDKNGT vẫn còn tồn tại nhiều hạn chế như: Chất lượng lập kế hoạch GDKNGT cho HS tiểu học tại thành phố Tuyên Quang chưa được các nhà trường đặc biệt quan tâm, chú trọng; Chất lượng công tác quản lý GDKNGT còn nhiều tồn tại: công tác chỉ đạo, hình thức GDKNGT cho HS qua các môn học thực hiện chưa tốt; Xây dựng thực hiện nội dung hoạt động GDKNGT cho HS lồng ghép với công tác sinh hoạt chủ nhiệm lớp; Chỉ đạo tích hợp nội dung hoạt động GDKNGT với hoạt động giáo dục ngoài giờ lên lớp chưa phong phú... Tổng hợp các tiêu chí xếp ở mức độ trung bình. Các nhà trường chưa quan tâm đúng mức tới công tác kiểm tra hoạt động GDKNGT, chưa có kế hoạch cụ thể, chưa xây dựng thành một mục riêng mà còn lồng ghép vào các nội dung kiểm tra khác của nhà trường. Hiệu trưởng một số trường Tiểu học tại thành phố Tuyên Quang chưa thực sự quan tâm tới công tác kiểm tra, đánh giá hoạt động GDKNGT cho HS, nội dung kiểm tra vẫn còn mang tính hình thức. 


\section{TÀI LIỆU THAM KHẢO}

1. Bộ Giáo dục và Đào tạo (2013), Tài liệu tham khảo giáo dục kĩ năng sống cho HS tiểu học - Tài liệu hướng dẫn giáo viên.

2. Bộ Giáo dục và Đào tạo (2018), Chuoong trình giáo dục phổ thông tổng thể, được ban hành theo Thông tu số 32/2018/TT-BGDĐT ngày 26/12/2018.
3. Trần Kiểm (2008), Nhũng vấn đề co bản của khoa học Quản lý giáo duc, NXB Đại học Sư phạm. 4. Nguyễn Thị Mỹ Lộc, Đinh Thị Kim Thoa, Bùi Thị Thúy Hằng (2010), Giáo dục giá trị sống và kĩ năng sống cho học sinh tiểu học, Tài liệu dành cho giáo iên tiểu học, NXB Đại học Quốc gia Hà Nội.

5. Nguyễn Văn Lũy, Lê Quang Sơn (2014), Giao tiếp su phạm, NXB Đại học Sư phạm.

\section{The situation of educational management of communication skills for primary students in Tuyen Quang city according to the orientation of the general educational program 2018}

Hoang Tra My

Article info

Recieved:

$2 / 5 / 2020$

Accepted:

$10 / 6 / 2020$

Keywords:

survey, assess,

management of

communication skills,

primary students

\begin{abstract}
In order to properly assess the situation of educational management of communication skills for primary students in Tuyen Quang city according to the orientation of the general educational program 2018, the author has surveyed the management situation objectively on the subjects: administrators, teachers ,teachers in charge of Young Pioneer, students' parents, in order to properly assess the situation of educational management of communication skills and propose appropriate solutions for educational management of communication skills to improve the quality of teaching communication skills in Primary schools in Tuyen Quang city according to the orientation of the general educational program 2018.
\end{abstract}

